\title{
$\mathrm{HCCl}$ Combustion: Analysis and Experiments
}

Salvador M. Aceves, Daniel L. Flowers, Joel Martinez-Frias and J. Ray Smith Lawrence Livermore National Laboratory

Robert Dibble, Michael Au and James Girard

University of California Berkeley 
SAE routinely stocks printed papers for a period of three years following date of publication. Direct your orders to SAE Customer Sales and Satisfaction Department.

Quantity reprint rates can be obtained from the Customer Sales and Satisfaction Department.

To request permission to reprint a technical paper or permission to use copyrighted SAE publications in other works, contact the SAE Publications Group.

This article was prepared as an account of work sponsored by an agency of the United States

Government. Neither the United States Government nor any agency thereof, nor any of their employees, makes any warranty, express or implied, or assumes any legal liability or responsibility for the accuracy, completeness, or usefulness of any information, apparatus, product, or process disclosed, or represents that its use would not infringe privately owned rights. Reference herein to any specific commercial product, process, or service by trade name, trademark, manufacturer, or otherwise does not necessarily constitute or imply its endorsement, recommendation, or favoring by the United States Government or any agency thereof. The views and opinions of authors expressed herein do not necessarily state or reflect those of the United States Government or any agency thereof.

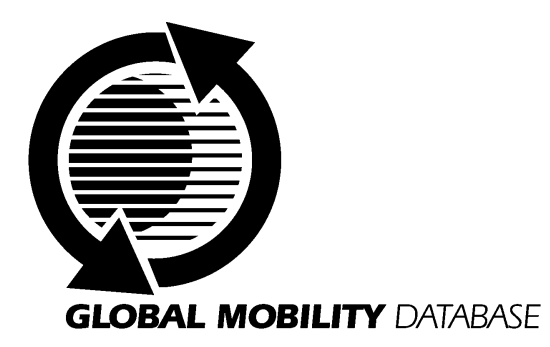

All SAE papers, standards, and selected books are abstracted and indexed in the Global Mobility Database

ISSN 0148-7191

No copyright is asserted in the works of U.S. Government employees.

Positions and opinions advanced in this paper are those of the author(s) and not necessarily those of SAE. The author is solely responsible for the content of the paper. A process is available by which discussions will be printed with the paper if it is published in SAE Transactions. For permission to publish this paper in full or in part, contact the SAE Publications Group.

Persons wishing to submit papers to be considered for presentation or publication through SAE should send the manuscript or a 300 word abstract of a proposed manuscript to: Secretary, Engineering Meetings Board, SAE.

\section{Printed in USA}




\title{
$\mathrm{HCCl}$ Combustion: Analysis and Experiments
}

\author{
Salvador M. Aceves, Daniel L. Flowers, Joel Martinez-Frias and J. Ray Smith \\ Lawrence Livermore National Laboratory
}

\author{
Robert Dibble, Michael Au and James Girard
}

University of California Berkeley

No copyright is asserted in the works of U.S. Government employees.

\begin{abstract}
Homogeneous charge compression ignition $(\mathrm{HCCl})$ is a new combustion technology that may develop as an alternative to diesel engines with high efficiency and low $\mathrm{NO}_{\mathrm{x}}$ and particulate matter emissions. This paper describes the $\mathrm{HCCl}$ research activities being currently pursued at Lawrence Livermore National Laboratory and at the University of California Berkeley. Current activities include analysis as well as experimental work.
\end{abstract}

On analysis, we have developed two powerful tools: a single zone model and a multi-zone model. The single zone model has proven very successful in predicting start of combustion and providing reasonable estimates for peak cylinder pressure, indicated efficiency and $\mathrm{NO}_{\mathrm{x}}$ emissions. This model is being applied to develop detailed engine performance maps and control strategies, and to analyze the problem of engine startability. The multi-zone model is capable of very accurate predictions of the combustion process, including $\mathrm{HC}$ and $\mathrm{CO}$ emissions. The multi-zone model has applicability to the optimization of combustion chamber geometry and operating conditions to achieve controlled combustion at high efficiency and low emissions.

On experimental work, we have done a thorough evaluation of operating conditions in a 4-cylinder Volkswagen TDI engine. The engine has been operated over a wide range of conditions by adjusting the intake temperature and the fuel flow rate. Satisfactory operation has been obtained over a wide range of operating conditions. Cylinder-to-cylinder variations play an important role in limiting maximum power, and should be controlled to achieve satisfactory performance.

\section{INTRODUCTION}

Homogeneous Charge Compression Ignition $(\mathrm{HCCl})$ is a combustion process that has the potential to be both highly efficient and low emission. $\mathrm{HCCl}$ can provide high, diesel-like efficiencies using gasoline, diesel fuel, and most alternative fuels, while producing ultra-low emissions of NOx and particulate matter. In some regards, $\mathrm{HCCl}$ incorporates the best features of both spark ignition (SI) gasoline engines using gasoline and diesel engines using diesel fuel. Like an SI engine the charge is well mixed which minimizes particulate emissions, and like a diesel engine it is compression ignited and has no throttling losses, which leads to high efficiency. However, unlike either of these conventional engines, combustion occurs simultaneously throughout the cylinder volume rather than in a flame front. $\mathrm{HCCl}$ engines have the potential to be lower cost than diesel engines because they would likely use a lower-pressure fuel-injection system.

$\mathrm{HCCl}$ is potentially applicable to both automotive and heavy truck engines. In fact, it could be scaled to virtually every size-class of transportation engines from small motorcycle to large ship engines. $\mathrm{HCCl}$ is also applicable to piston engines used outside the transportation sector such as those used for electrical power generation and pipeline pumping. $\mathrm{HCCl}$ engines are particularly well suited to hybrid vehicle applications because the engine is optimized for operation over a more limited range of speeds and loads compared to engines used in conventional power trains. Use of $\mathrm{HCCl}$ engines in hybrid vehicles could leverage the existing benefits of $\mathrm{HCCl}$ to create highly fuel-efficient vehicles.

This paper describes the past, current and future $\mathrm{HCCl}$ research activities at Lawrence Livermore National Laboratory (LLNL) and at the University of California at Berkeley. The LLNL activities have had considerable success in doing detailed modeling of $\mathrm{HCCl}$ combustion, studying the fundamentals of $\mathrm{HCCl}$ combustion, and in finding optimum operating conditions for $\mathrm{HCCl}$ engine operation. The experimental work is dedicated to testing a single cylinder engine representative of heavy truck engines, and a small, high-speed four-cylinder engine representative of automotive applications. Current research, both analytical and experimental, is directed at solving the most important problems associated with 
$\mathrm{HCCl}$ engine operation: control, startability, emissions of hydrocarbon and carbon monoxide, power density, and transition to other modes of operation. In addition to this, the LLNL work on $\mathrm{HCCl}$ is done in collaboration with UC Berkeley, and it is contributing to the education of future $\mathrm{HCCl}$ engineers. By the end of this year, four graduate students will have obtained degrees as a direct result of this collaboration.

The LLNL/Berkeley project is divided into two major tasks. Task 1 is to simulate the $\mathrm{HCCl}$ combustion process to predict the efficiency, emissions and optimum engine design parameters. In Task 2 we verify the simulation by operating an engine in the $\mathrm{HCCl}$ mode and measure the efficiency, emissions and performance of the engine.

\section{Analysis of $\mathrm{HCCl}$ Combustion}

Over the last few years, a consensus has developed as to the nature of $\mathrm{HCCl}$ combustion. It is now generally agreed that $\mathrm{HCCl}$ combustion is dominated by local chemical-kinetic reaction rates [1], with no requirement for flame propagation. This notion has been supported by spectroscopic data indicating that the order of radical formation in $\mathrm{HCCl}$ combustion corresponds to selfignition rather than flame propagation $[2,3]$. Recent analytical developments also support the view that $\mathrm{HCCl}$ combustion is dominated by chemical kinetics, and an analysis methodology based on this premise has had considerable success in predicting $\mathrm{HCCl}$ combustion and emissions [4]. If a truly homogeneous mixture exists at the time of combustion, turbulence has little direct effect on $\mathrm{HCCl}$ combustion, but it may have an indirect effect by altering the temperature distribution and the boundary layer thickness within the cylinder. Small temperature differences inside the cylinder have a considerable effect on combustion because chemical kinetics is very sensitive to temperature. As a result, heat transfer and mixing are important in forming the condition of the charge prior to ignition. However, they play a secondary role during the $\mathrm{HCCl}$ combustion process itself because $\mathrm{HCCl}$ combustion is very rapid.

Turbulence introduces great complexity to the analysis of spark-ignited and diesel engines. The fact that $\mathrm{HCCl}$ combustion is not very sensitive to turbulence makes it possible to develop a thorough, accurate method of analysis of $\mathrm{HCCl}$ combustion. This constitutes a great advantage for $\mathrm{HCCl}$ engines, since analysis then becomes a very powerful tool to advance the technology. $\mathrm{HCCl}$ combustion can be analyzed with better accuracy than ever achieved for spark-ignited or diesel engines. Analysis can therefore be used as an important tool in the design of $\mathrm{HCCl}$ engines and in the evaluation of control strategies for $\mathrm{HCCl}$ engines.

During the past year we have developed two powerful $\mathrm{HCCl}$ analysis tools: a single zone HCT model and a multi-zone HCT model. The single zone model has proven very successful in predicting start of combustion and providing reasonable estimates for peak cylinder pressure, indicated efficiency and $\mathrm{NO}_{x}$ emissions, with very little computational cost $(5$ minutes on an engineering workstation) [5]. The multi-zone model is capable of very accurate predictions of the combustion process, including $\mathrm{HC}$ and $\mathrm{CO}$ emissions, at the cost of longer running times (2 hours on an engineering workstation). The two models complement each other very nicely. Most of the work can be done with the single zone model, and the multi-zone model can be used for a detailed analysis of important operating points and to do parametric studies of engine geometry or operating conditions on $\mathrm{HCCl}$ combustion.

THE SINGLE ZONE MODEL - The single zone model uses a detailed chemical kinetics code (HCT, Hydrodynamics, Chemistry and Transport [6]) to predict $\mathrm{HCCl}$ combustion, under the assumption that temperature, pressure and composition are uniform throughout the combustion chamber. This model is being applied to develop detailed engine performance maps and control strategies, and to analyze the problem of engine startability. For this application, our single zone model has been extended to include overall system models as required to achieve the desired control. The single zone model has also been linked to an optimizer (titled SUPERCODE) to calculate optimum operating conditions for any combination of desired speed and load. This is a powerful tool that is now being applied to optimization of $\mathrm{HCCl}$ engine control strategies.

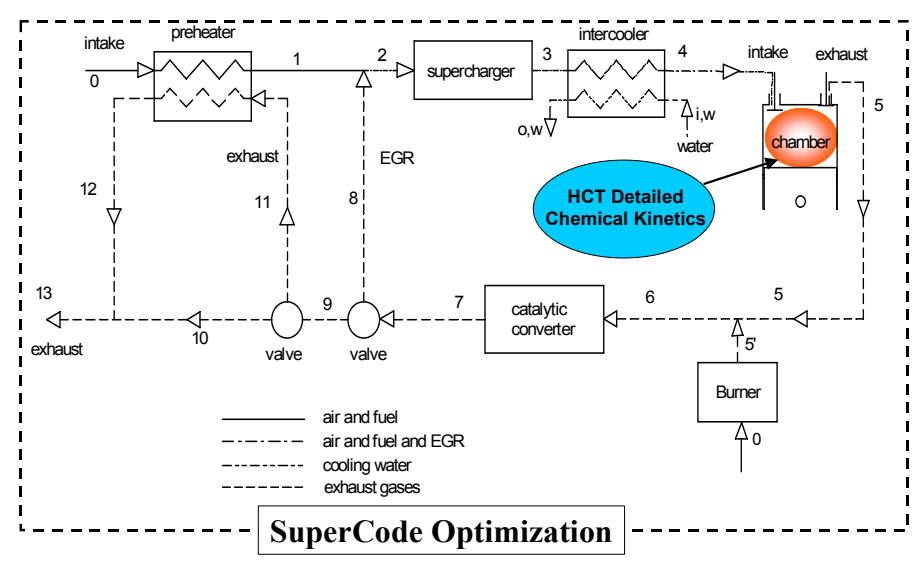

Figure 1. Schematic of thermal system for control of $\mathrm{HCCl}$ combustion [7].

An example of a system that has been analyzed to achieve $\mathrm{HCCl}$ operation over a wide range of operating conditions is a purely thermal control system, where thermal energy from EGR and compression work in the supercharger are either recycled or rejected as needed [7]. A schematic of this system is shown in Figure 1. Thermal control is inexpensive to implement and purely based on technologies familiar to manufactures and may be acceptable if demonstrated to be satisfactory. The thermal control system consists of a preheater to increase fuel-air mixture temperature, a supercharger to increase mixture density and an intercooler to decrease 
mixture temperature. The resulting system has five independent control parameters: equivalence ratio, fraction of EGR, intake pressure, preheater effectiveness, and intercooler effectiveness. These parameters can be tuned to meet the load demands while obtaining auto-ignition at the desired time in the engine cycle and meeting the constraints of maximum pressure and $\mathrm{NO}_{\mathrm{x}}$ emissions.

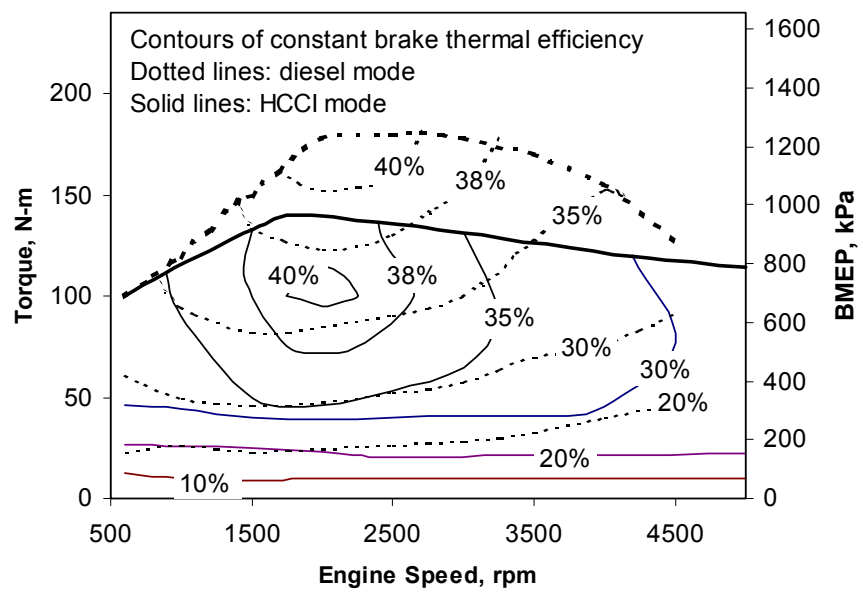

Figure 2. Performance map for the Volkswagen TDI 4-cylinder engine, showing contours of constant brake thermal efficiency [7]. Dotted lines: diesel mode. Solid lines: $\mathrm{HCCl}$ mode. Lines of maximum torque are also shown for the diesel and $\mathrm{HCCl}$ mode as thicker lines.

Figure 2 shows the optimized performance map for the $\mathrm{HCCl}$ engine operating with a thermal control system. Figure 2 shows lines of constant brake thermal efficiency as a function of torque and rpm. The figure shows solid lines representing constant efficiency for the engine in $\mathrm{HCCl}$ mode. Overlaid on the figure are dotted lines, which represent the efficiency of the same engine (Volkswagen TDI) engine in diesel mode. The engine working on $\mathrm{HCCl}$ mode is more efficient for low torque at any engine speed than the engine working in diesel mode. The engine has a higher efficiency in $\mathrm{HCCl}$ mode because of the faster combustion obtained with $\mathrm{HCCl}$ combustion (approaching the ideal Otto cycle), and the need to delay combustion to reduce $\mathrm{NO}_{\mathrm{x}}$ emissions in the diesel engine. The $\mathrm{HCCl}$ engine has $72 \%$ of the maximum torque obtained by the diesel engine, and $88 \%$ of the power of the diesel engine, while producing practically zero particulate matter and less than 100 parts per million of $\mathrm{NO}_{x}$ under all operating conditions. Although this simulation has not been validated, it clearly shows the potential of $\mathrm{HCCl}$ operation.

Current and future applications of the single-zone model are focused on other forms of control for $\mathrm{HCCl}$ engines (variable valve timing, variable compression ratio, fuel additives) that may be used to achieve satisfactory transient operation over a wide range of conditions.
THE MULTI-ZONE MODEL - This model can be used to do detailed performance analyses and to study fundamentals of $\mathrm{HCCl}$ combustion. The multi-zone model can take full account of the effect of temperature (and possibly concentration) gradients inside the combustion chamber. The multi-zone model combines a detailed fluid mechanics code with a detailed chemical kinetics code. Instead of directly linking the two codes, which would require an unacceptably long computational time, the procedure consists of first running the fluid mechanics code to obtain temperature profiles as a function of time. These temperature profiles are then used as input to a multi-zone chemical kinetics code. The advantage of this procedure is that a small number of zones (10) are enough to obtain accurate results. This procedure achieves the benefits of linking the fluid mechanics and the chemical kinetics codes while at the same time reduces the computational effort to a level that can be handled with current computers. The success of this procedure is in large part a consequence of the fact that for much of the compression stroke the chemistry is inactive and thus has little influence on fluid mechanics and heat transfer. Then, when chemistry is active, combustion is rather sudden, leaving little time for interaction between chemistry and fluid mixing and heat transfer. This sequential methodology has been capable of explaining the main characteristics of $\mathrm{HCCl}$ combustion that have been observed in experiments.

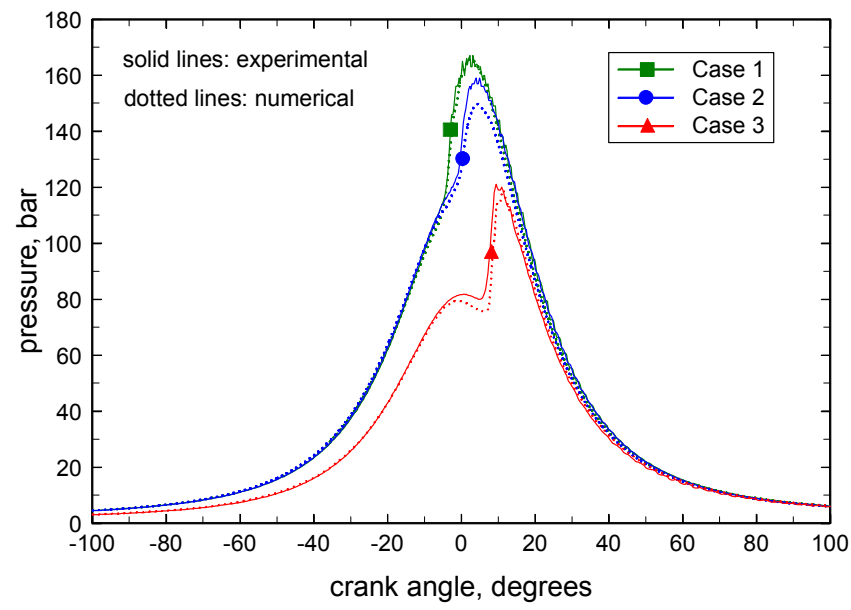

Figure 3. Experimental and numerical pressure traces for three cases of propane $\mathrm{HCCl}$ combustion. Dotted lines represent numerical results and solid lines show experimental results [8].

Some recent results of the multi-zone model are presented in Figures 3 and 4 . Figure 3 shows a comparison between experimental pressure traces and calculated pressure traces for three cases of propane $\mathrm{HCCl}$ combustion. Figure 3 shows an almost perfect agreement between experimental and numerical 
pressure traces for Cases 1 and 3 . The agreement holds during the compression stroke as well as during the expansion stroke. The multi-zone model has also resulted in excellent predictions for the apparent heat release rates for these cases [8]. Heat release rate is typically difficult to match analytically because heat release rate is obtained by analyzing pressure traces according to the first law of thermodynamics. Small inaccuracies in pressure can therefore result in great differences in apparent heat release rates. Accurate prediction of heat release rates is possible for $\mathrm{HCCl}$ combustion because $\mathrm{HCCl}$ combustion is relatively insensitive to turbulence. Turbulence, flame propagation and mixing make $\mathrm{SI}$ and $\mathrm{Cl}$ combustion much more difficult to predict with good accuracy than $\mathrm{HCCl}$ combustion. The multi-zone model also has the capability of making predictions of hydrocarbon and carbon monoxide emissions and to study the effect of cylinder geometry on engine emissions. The multi-zone model also indicates that hydrocarbon and carbon monoxide emissions originate in the crevices and boundary layer, which are too cold to react. Nitrogen oxides originate in the central core, where temperatures are highest. This information alone gives the engine designer guidance on what geometries will have the lowest emissions.

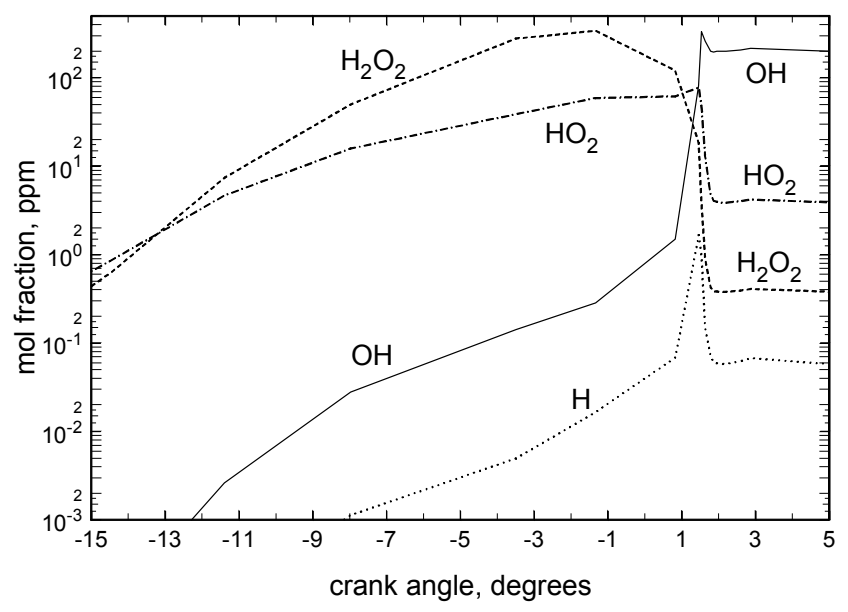

Figure 4. Concentration of $\mathrm{H}_{2} \mathrm{O}_{2}$ and radicals $\mathrm{H}, \mathrm{OH}$, and $\mathrm{HO}_{2}$ in parts per million as a function of crank angle, from [4].

The multi-zone model has also performed an important role in studying the chemical and physical fundamentals of $\mathrm{HCCl}$ combustion. Figure 4 shows the concentration of $\mathrm{H}_{2} \mathrm{O}_{2}$ and radicals $\mathrm{H}, \mathrm{OH}$ and $\mathrm{HO}_{2}$ as a function of crank angle during $\mathrm{HCCl}$ combustion. These radicals are selected as the most important for driving the ignition process. In general terms, $\mathrm{HCCl}$ ignition occurs when hydrogen peroxide $\left(\mathrm{H}_{2} \mathrm{O}_{2}\right)$ that has been accumulating in the reactive mixture begins to decompose at a significant rate, producing two hydroxyl $(\mathrm{OH})$ radicals for each $\mathrm{H}_{2} \mathrm{O}_{2}$ that decomposes. This reaction releases an enormous number of $\mathrm{OH}$ radicals, most of which then react with fuel molecules, producing water and heat, increasing the temperature of the reacting mixture and setting in motion a very effective chain branching sequence. The importance of this reaction is clearly seen in Figure 4, where the concentration of $\mathrm{H}_{2} \mathrm{O}_{2}$ decreases rapidly as $\mathrm{OH}$ is being formed. Hydrogen peroxide decomposition occurs at a temperature range between 1050 and 1100 $\mathrm{K}$. This fundamental chemistry of $\mathrm{HCCl}$ auto-ignition and combustion is identical to the chemistry of knock in spark-ignited engines. "Active radicals" present in the exhaust gases do not survive the exhaust and intake strokes, and play a very minor role in starting $\mathrm{HCCl}$ combustion.

For future work, the multi-zone model will be used for detailed analyses of operating points selected as optimum by the single zone model. The results will determine a very accurate picture of all the important operating parameters of $\mathrm{HCCl}$ combustion (peak cylinder pressure, indicated efficiency, $\mathrm{NO}_{x}, \mathrm{CO}$ and $\mathrm{HC}$ emissions). The results for $\mathrm{HC}$ and $\mathrm{CO}$ emissions obtained from the multi-zone model will be used to determine the required characteristics of a catalytic converter that will oxidize enough of these pollutants to meet the desired emissions standards.

\section{$\mathrm{HCCl}$ Experiments}

The engine experiments are being done to validate the application of the analysis code, and to implement strategies for $\mathrm{HCCl}$ engine startability and control. Our first experimental prototype was a CFR engine. The CFR engine is a rugged, variable compression ratio engine, which is very well suited for $\mathrm{HCCl}$ operation. An engine performance map was developed based on the CFR experiments. An analysis of the experimental conditions was conducted, and very good agreement was obtained between the experimental and numerical results [9].

Current work is focused on a 4 cylinder Volkswagen TDI engine operating in $\mathrm{HCCl}$ mode (See Figure 5). This engine has operated in multi-cylinder $\mathrm{HCCl}$ mode since October of 1999 (see pressure traces in Figure 6). Operating an $\mathrm{HCCl}$ engine in multi-cylinder mode is more difficult than running a single cylinder engine in $\mathrm{HCCl}$ mode. This is because $\mathrm{HCCl}$ combustion is very sensitive to temperature. Small differences in temperature from one cylinder to the next can cause a colder cylinder to misfire or a hotter cylinder to ignite very early.

The TDI engine represents a modern, high efficiency, high-speed small displacement diesel engine and is currently available as an option in several Volkswagen passenger cars. This engine is equipped with in-cylinder pressure transducers and other instrumentation for performance measurements, such as an in-line torque transducer that allows for highly accurate measurement of brake power, specific emissions and fuel 
consumption. Emissions measurement equipment is available in the Engine Laboratory to quantify $\mathrm{NO}, \mathrm{NO}_{2}$, $\mathrm{CO}, \mathrm{CO}_{2}, \mathrm{O}_{2}$ and hydrocarbons using a flame ionization detector (FID). Experiments are being performed on the TDI engine to investigate and validate control strategies for stable $\mathrm{HCCl}$ operation over a wide range of speed and load conditions. Experiments investigating control of multi-cylinder interactions and cylinder-to-cylinder variations are being performed.

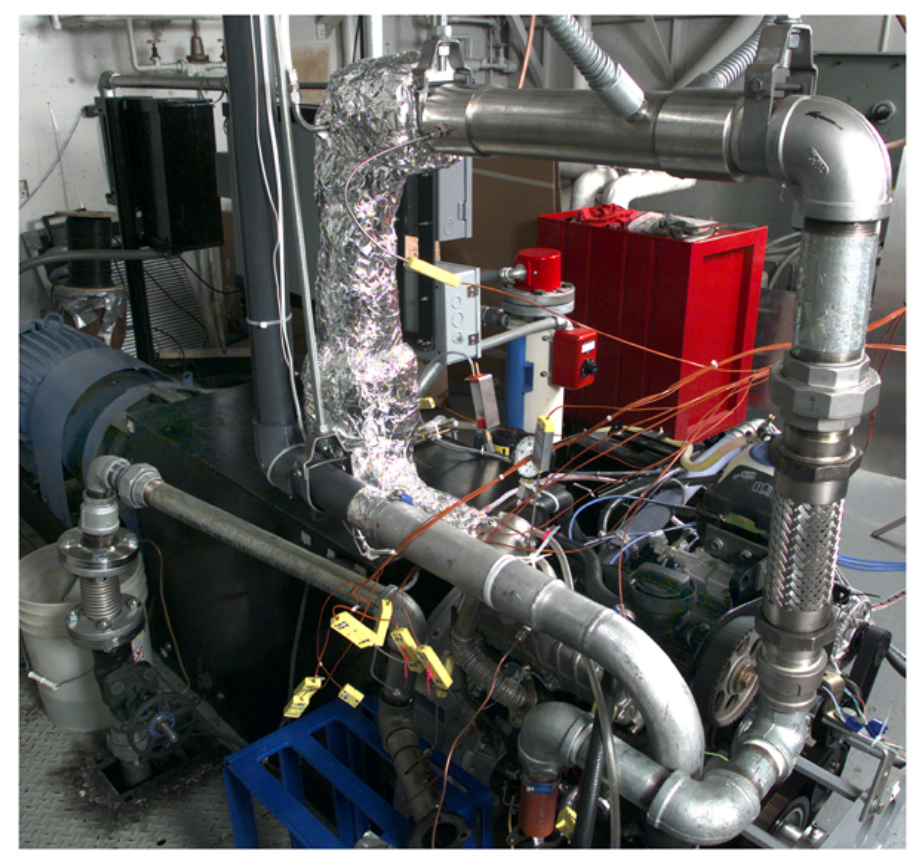

Figure 5. The Volkswagen TDI engine converted to $\mathrm{HCCl}$ mode.

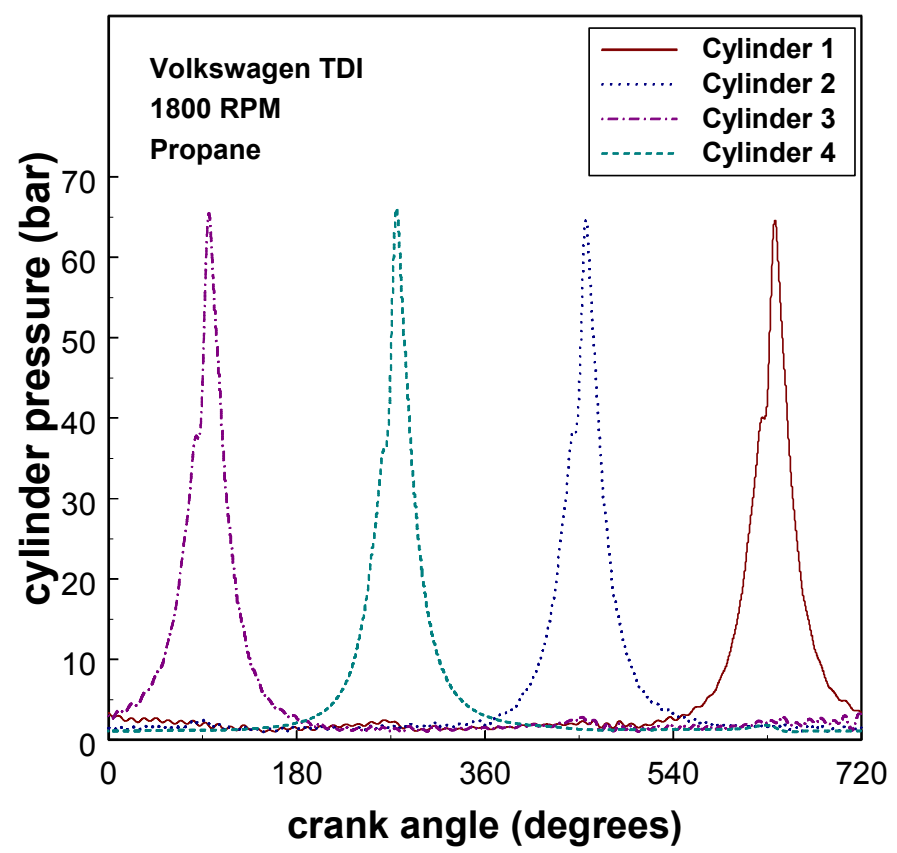

Figure 6. Pressure traces for the four cylinders of the Volkswagen TDI engine operating in $\mathrm{HCCl}$ mode.
Figures 7 and 8 show recent results that have been obtained with the TDI engine [10]. Experiments have been conducted for naturally aspirated operation with propane fuel. The engine performance, combustion process, and emissions are monitored for variations in intake temperature and fuel flow rate. The engine has been operated over a wide range of conditions. The intake temperature ranges from roughly $105^{\circ} \mathrm{C}$ to $145^{\circ} \mathrm{C}$. Five different fuel flow rates have been studied: $0.34 \mathrm{~g} / \mathrm{s}$, $0.50 \mathrm{~g} / \mathrm{s}, 0.65 \mathrm{~g} / \mathrm{s}, 0.72 \mathrm{~g} / \mathrm{s}$, and $0.83 \mathrm{~g} / \mathrm{s}$.

Figure 7 shows the brake mean effective pressure (BMEP) versus intake manifold temperature. The BMEP ranges from -0.8 bar to 3.3 bar for this operating range. The idle (0 bar BMEP) operating point occurs at $0.34 \mathrm{~g} / \mathrm{s}$ fuel flow rate and an intake temperature of roughly 130 ${ }^{\circ} \mathrm{C}$. The combustion efficiency at this idle operating point is around $75 \%$. The THC and $\mathrm{CO}$ emissions for this point are unacceptably high. It may be possible to improve combustion efficiency by going to a lower fuel flow rate and a higher intake temperature. For the high load operating points, the trend is that lower intake temperature results in higher BMEP. Ignoring the lowest temperature operating point for $0.65 \mathrm{~g} / \mathrm{s}$ fuel flow rate (which is relatively unstable), the three highest fuel flow rates, $0.65,0.72$, and $0.83 \mathrm{~g} / \mathrm{s}$ have the same trend. The brake thermal efficiency obtained for these conditions ranges from less than zero (negative efficiency meaning that work must be added to the engine by the electric motor to sustain operation) to $25 \%$. The maximum gross indicated thermal efficiency is $32 \%$. The indicated efficiency is low despite the high compression ratio, likely due to a combustion chamber design (high swirl, very little clearance between the piston top and head at TDC) that results in significant heat transfer.

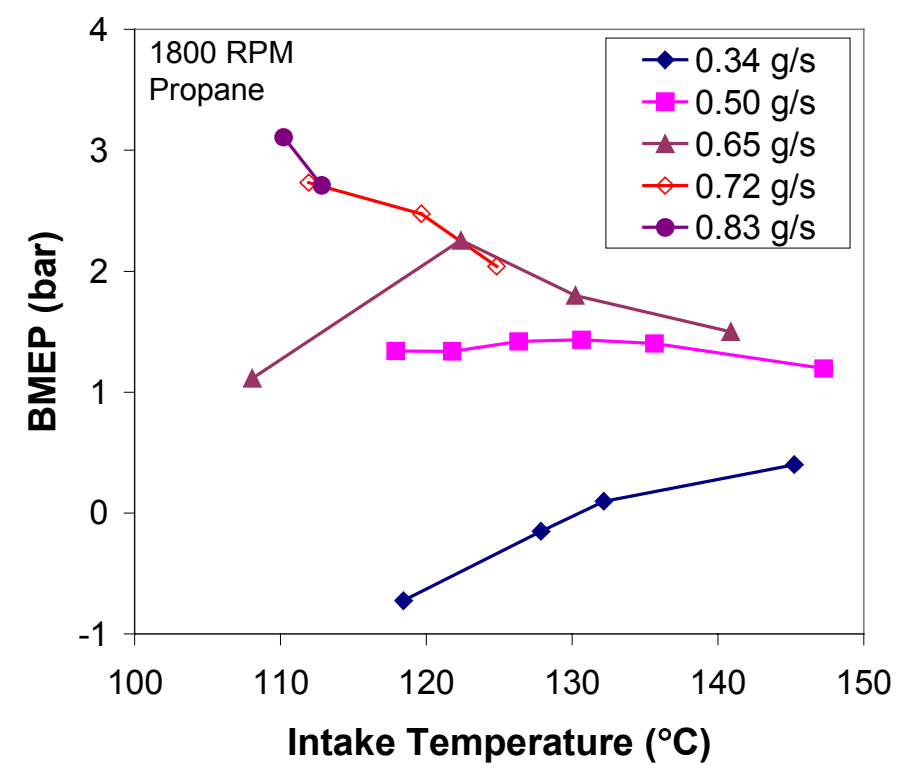

Figure 7. BMEP versus intake manifold temperature for the Volkswagen TDI engine operating over a wide range of intake temperatures and fuel flow rates in $\mathrm{HCCl}$ mode with propane fuel [10]. 
Figure 8 shows pressure traces for each cylinder at four different intake manifold temperatures at $0.65 \mathrm{~g} / \mathrm{s}$ fuel flow rate. The pressure traces are an average of 332 instantaneous traces. The lowest temperature operating point, $108^{\circ} \mathrm{C}$ intake temperature, operation can be seen to be very inconsistent between the cylinders. Operation around the lower limits is very tenuous, and the difference between stable operation and misfire requires only a small change in the control parameters. Slight variations in cooling water temperature, oil temperature, compression ratio of each cylinder, intake manifold temperature inhomogeneities could result in significant variations in the combustion process. For example, in the VW TDI engine the cooling water runs longitudinally through the engine entering near cylinder 1 and exiting at cylinder 4. This could result in a higher water temperature gradient along the engine, resulting in variations in heat transfer throughout the engine. The $108^{\circ} \mathrm{C}$ operating point may be near the lower limit of operation, and the slight differences in the parameters mentioned above could explain this inconsistent operation.
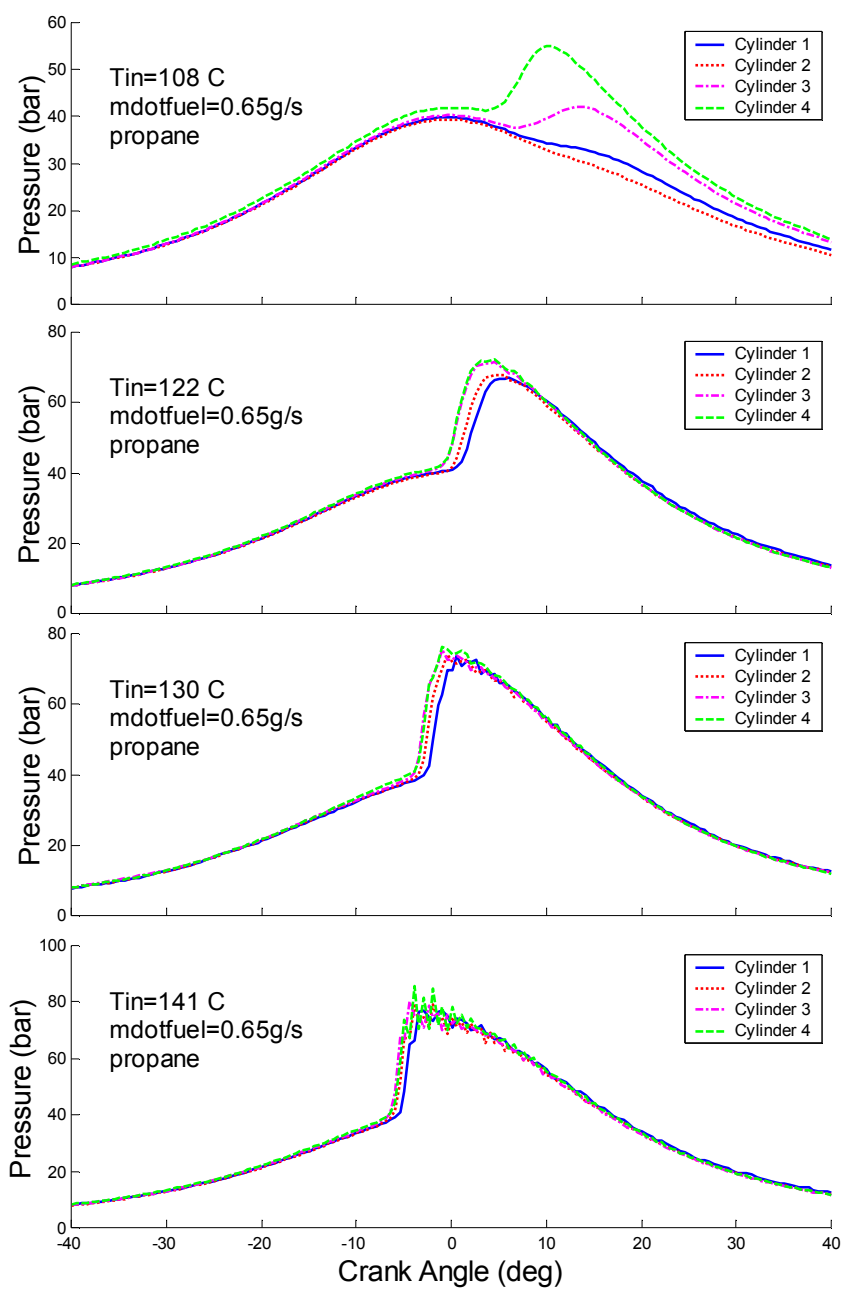

Figure 8. Pressure traces for four different intake manifold temperatures at $0.65 \mathrm{~g} / \mathrm{s}$ fuel flow rate (average of 332 instantaneous traces), for the Volkswagen TDI engine operating in $\mathrm{HCCl}$ mode on propane fuel [10].
Figure 8 shows that as the intake temperature is increased the combustion process becomes more consistent among the cylinders. At the highest temperature in the range $\left(141^{\circ} \mathrm{C}\right)$ there is little difference between the cylinder pressure traces, but combustion is very advanced, and significant pressure oscillations (knock) are observed. The pressure oscillations set an upper limit to the intake temperature for satisfactory combustion. The results of Figure 8 show that controlling individual cylinders requires a strategy strong enough to overcome a variety of operating factors.

The TDI engine combustion chambers will be modified from the current bowl-in-piston chamber to a pancake combustion chamber by installing flat-top pistons. This change will significantly improve overall combustion performance by reducing heat transfer. Other modifications to the intake and exhaust system will be done to achieve $\mathrm{HCCl}$ operation.

In addition to the TDI engine, we have a Caterpillar 3401 engine that has been converted to $\mathrm{HCCl}$ mode. The Caterpillar 3401 is representative of a family of engines that can be applied to heavy-duty trucks. In-cylinder pressure measurements will allow direct comparison with the HCT simulations of the start of combustion, heat release rate, and IMEP. Engine-out emissions will also be compared to the simulations.

The converted Caterpillar 3401 engine will be run in $\mathrm{HCCl}$ mode over a wide range of operating conditions with multiple fuels (methane, propane, natural gas, etc.) to analyze engine performance and validate our models. The use of a large-displacement, single-cylinder engine such as this makes it easier to obtain good quality data necessary for model validation. This engine will be equipped to handle intake heating, EGR, and fuel additives. Experiments will be performed to further study these control options. Because in-cylinder pressure transducers may be impractical for production engines, investigation into the use of low-cost, block-mounted sensors for detection of peak pressure rise and peak heat release will be performed. Control strategies can be developed and tested on the single-cylinder engine before being implemented in the more complicated environment of the multi-cylinder TDI engine. Strategies for starting the engine will also be analyzed. Some possibilities are additives (DME, diesel, etc.), intake preheating, and variable compression ratio.

\section{CONCLUSIONS}

This paper presents a summary of the $\mathrm{HCCl}$ research activities being currently pursued at Lawrence Livermore National Laboratory and at the University of California Berkeley. Current activities include analysis as well as experimental work. Current activities and the main results obtained to date are summarized next.

We have developed a single zone detailed chemical kinetics model for analysis of $\mathrm{HCCl}$ combustion. This model has proven very successful in predicting start of 
combustion and providing reasonable estimates for peak cylinder pressure, indicated efficiency and $\mathrm{NO}_{\mathrm{X}}$ emissions. This model is being applied to develop detailed engine performance maps and control strategies, and to analyze the problem of engine startability. The single zone model has also been linked to an optimizer (titled SUPERCODE) to calculate optimum operating conditions for any combination of desired speed and load. This is a powerful tool that is now being applied to optimization of $\mathrm{HCCl}$ engine control strategies.

We have also developed a multi-zone detailed chemical kinetics model, which takes into account the temperature (and possibly concentration) gradients that exist inside the combustion chamber. The multi-zone model is capable of very accurate predictions of the combustion process, including $\mathrm{HC}$ and $\mathrm{CO}$ emissions. The multizone model has applicability to the optimization of combustion chamber geometry and operating conditions to achieve controlled combustion at high efficiency and low emissions.

On experimental work, we have done a thorough evaluation of operating conditions in a 4-cylinder Volkswagen TDI engine. The engine has been operated over a wide range of conditions by adjusting the intake temperature and the fuel flow rate. Satisfactory operation has been obtained over a wide range of operating conditions. Cylinder-to-cylinder variations play an important role in limiting maximum power, and should be controlled to achieve satisfactory performance.

\section{REFERENCES}

1. Najt, P. M. and Foster, D. E., "Compression-Ignited Homogeneous Charge Combustion," SAE paper 830264, 1983.

2. Noguchi, M., Tanaka, Y., Tanaka, T., and Takeuchi, Y., "A Study on Gasoline Engine Combustion by Observation of Intermediate Reactive Products During Combustion," SAE paper 790840, 1979.
3. lida, N., "Alternative Fuels and Homogeneous Charge Compression Ignition Combustion Technology," SAE paper 972071, 1997.

4. Aceves, S. M., Flowers, D. L., Westbrook, C. K., Smith, J. R., Pitz, W., Dibble, R., Christensen, M., and Johansson, B., "A Multi-Zone Model for Prediction of $\mathrm{HCCl}$ Combustion and Emissions," SAE paper no. 2000-01-0327, 2000.

5. Flowers, D. L., Aceves, S. M., Westbrook, C. K., Smith, J. R., and Dibble, R. W., "Sensitivity of Natural Gas $\mathrm{HCCl}$ Combustion to Fuel and Operating Parameters Using Detailed Kinetic Modeling," In AES-Vol. 39, "Proceedings of the ASME Advanced Energy Systems Division - 1999," Edited by S. M. Aceves, S. Garimella and R. Peterson, pp. 465-473, 1999.

6. Lund, C. M., 1978 "HCT - A General Computer Program for Calculating Time-Dependent Phenomena Involving One-Dimensional Hydrodynamics, Transport, and Detailed Chemical Kinetics," Lawrence Livermore National Laboratory report UCRL-52504.

7. Martinez-Frias, J., Aceves, S.M., Flowers, D., Smith, J.R., and Dibble, R., 2000, "HCCl Engine Control by Thermal Management," SAE Paper 2000-01-2869.

8. Aceves, S.M., Flowers, D.L., Martinez-Frias, J., Smith, J.R., Westbrook, C., Pitz, W., Dibble, R., Wright, J., Akinyemi, W.C., and Hessel, R.P., "A Sequential Fluid-Mechanic Chemical-Kinetic Model of Propane $\mathrm{HCCl}$ Combustion," SAE Paper 2001-011027.

9. Flowers, D., Aceves, S.M., Smith, R., Torres, J., Girard, J., and Dibble, R., "HCCl In A CFR Engine: Experiments And Detailed Kinetic Modeling," SAE Paper 2000-01-0328.

10. Flowers, D., Aceves, S.M., Martinez-Frias, J., Smith, R., Au, M., Girard, J., and Dibble, R., "Operation of a Four-Cylinder 1.9L Propane Fueled Homogeneous Charge Compression Ignition Engine: Basic Operating Characteristics and Cylinder-to-Cylinder Effects," SAE Paper 2001-01-1894. 